\title{
GAMBARAN PENGETAHUAN DAN PERILAKU CUCI TANGAN PAKAI SABUN (CTPS) PADA SISWA SEKOLAH DASAR DI WILAYAH KERJA PUSKESMAS GEDONG TATAAN
}

\author{
Birgitta Merlina ${ }^{1)}$
}

\begin{abstract}
Abstrak
Cuci tangan pakai sabun (CCTPS) merupakan tindakan membersihkan tangan dan jari jemari menggunakan sabun dan air mengalir. CPTS juga untuk memutuskan mata rantai penularan penyakit. Tujuan penelitian mengetahui gambaran pengetahuan dan perilaku CTPS pada siswa sekolah dasar di wilayah kerja Puskesmas Gedong Tataan. Variabel yang diteliti adalah pengetahuan, fasilitas, dan perilaku CPTS.

Dari hasil penelitian mendapatkan sebanyak $69,2 \%$ siswa memiliki pengetahuan yang baik, dan $53,3 \%$ memiliki perilaku yang baik dalam CTPS. Sebanyak $25 \%(\mathrm{~N}=40)$ sekolah sudah tersedia fasilitas CTPS secara lengkap.

Perlu meningkatkan pengetahuan siswa dan guru sekolah melalui penyuluhan agar perilaku CTPS menjadi sebuah perilaku yang melekat pada anak sekolah. Menyiapkan fasilitas serta peraturan sekolah menjadi prasarana dalam menciptakan perubahan perilaku.
\end{abstract}

Kata kunci: pengetahuan, perilaku, fasilitas, CTPS

1)Alumni Prodi D3 Kesehatan Lingkungan Poltekkes Tanjungkarang

\section{PENDAHULUAN}

Kesehatan merupakan faktor yang paling penting dalam kehidupan manusia. Pembangunan kesehatan merupakan bagian dari integral pembangunan nasional. Pembangunan keschatan adalah upaya semua komponen bangsa untuk meningkatkan kesadaran, kemauan, dan kemampuan untuk hidup sehat bagi setiap orang agar terwujud derajat kesehatan masyarakat yang optimal (Kepmenkes RI, 2009).

Pembangunan kesehatan yang ingin dicapai oleh bangsa Indonesia adalah tercapainya bangsa yang maju dan mandiri, sejahtera lahir dan batin. Salah satu ciri bangsa yang maju adalah mempunyai derajat kesehatan yang tinggi, karena derajat kesehatan mempunyai pengaruh yang sangat besar terhadap kualitas sumber daya manusia.

Pengetahuan merupakan hasil yang dikemukakan oleh seseorang yang merupakan hasil dari tahu. Hal ini dapat terjadi setelah orang atau individu melakukan penginderaan terhadap objek tertentu. Penginderaan terjadi melalui panca indera manusia, yakni indera penglihatan, pendengaran, penciuman, rasa dan raba. Sebagaian besar hasil penginderaan manusia diperoleh melalui mata dan telinga (Notoatmodjo, 2003).
Perilaku seseorang akan terbentuk apabila seseorang tersebut melakukan proses interaksi dengan sesama dan lingkungan. Faktor yang paling berperan penting dalam membentuk perilaku seseorang terhadap respon atau rangsangan dari luar organisme (orang) tergantung pada karekteristik orang atau faktor dari orang yang bersangkutan tersebut. Faktorfaktor yang berperan dalam pembentukan perilaku dibedakan menjadi dua, yaitu faktor intern dan faktor ekstern. Faktor intern berupa kecerdasan, emosi dan sebagainya. Sedangkan faktor ekstern meliput objek, orang, kelompok dan hasil kebudayaan yang membentuk terwujudnya perilaku.

Terwujudnya derajat kesehatan tersebut dapat dicapai. Salah satunya dengan Perilaku Hidup Bersih dan Sehat (PHBS). PHBS merupakan upaya untuk memberikan pengalaman belajar atau menciptakan suatu kondisi bagi perorangan, keluarga, kelompok dan masyarakat yang membuka jalur komunikasi, memberi informasi untuk meningkatkan pengetahuan sikap dan perilaku melalui pendekatan, pimpinan, bina suasana dan pemberdayaan masyarakat.

PHBS merupakan cerminan pola hidup berkeluarga yang senantiasa memperhatikan dan menjaga kesehatan seluruh anggota 
keluarga. PHBS terwujud karena keberdayaan masyarakat yang sadar, mau dan mampu mempraktekkan PHBS. Penyakit yang dapat timbul akibat rendahnya PHBS dapat mengakibatkan rendahnya derajat kesehatan Indonesia dan rendahnya kualitas hidup sumber daya manusia. Upaya untuk pengembangan promosi kesehatan dan PHBS yang lebih terarah, terancam, terpadu dan berkesinambungan, dikembangkan melalui intergrasi promosi kesehatan sasaran utama adalah PHBS tatanan rumah tangga (individu, keluarga dan masyarakat) dan Institusi Pendidikan terutama tingkat sekolah dasar.

PHBS di sekolah adalah sekumpulan perilaku yang dipraktikkan oleh peserta didik, guru dan masyarakat lingkungan sekolah atas dasar kesadaran sebagai hasil belajar, sehingga secara mandiri mampu mencegah penyakit, meningkatkan kesehatannya, serta berperan aktif dalam mewujudkan lingkungan yang sehat. Anak sekolah merupakan generasi penerus bangsa yang perlu dijaga, ditingkatkan dan dilindungi kesehatannya. Jumlah usia sekolah yang cukup besar yaitu $30 \%$ dari jumlah penduduk Indonesia merupakan masa kecmasan untuk menanamkan PHBS sehingga anak sekolah berpotensi sebagai agen perubahan untuk mempromosikan PHBS, baik di lingkungan sekolah, keluarga maupun masyarakat. Dengan menerapkan PHBS di sekolah oleh peserta didik, guru, dan masyarakat lingkungan sekolah, maka akan membentuk mereka untuk memiliki kemampuan dan kemandirian dalam mencegah penyakit, meningkatkan keschatannya, serta berperan aktif dalam mewujudkan lingkungan sekolah yang sehat (Proverawati dan Rahmawati, 2012).

Munculnya berbagai penyakit yang sering menyerang anak usia sekolah (usia 6-12 tahun), ternyata umumnya berkaitan dengan PHBS. Penanaman nilai-nilai PHBS di sekolah merupakan kebutuhan mutlak dan dapat dilakukan melalui pendekatan usaha kesehatan sekolah (UKS). PHBS disekolah adalah upaya untuk memberdayakan siswa, guru, dan masyarakat lingkungan sekolah agar tahu, mau dan mampu mempraktikkan PHBS, dan berperan aktif dalam mewujudkan sekolah yang sehat. Indikator PHBS di sekolah yang meliputi: 1) Mencuci tangan dengan air yang mengalir dan memakai sabun; 2) Mengkonsumsi jajanan sehat di kantin sekolah; 3 Menggunakan jamban yang bersih dan sehat;
4) Olahraga yang teratur dan terukur; 5) Memberantas jentik nyamuk; 6) Tidak merokok; 7) Menimbang berat badan dan mengukur tinggi badan setiap bulan; 8) Membuang sampah pada tempatnya.

Cuci tangan merupakan salah satu tindakan sanitasi dengan membersihkan tangan dan jari dengan menggunakan air ataupun cairan lainnya dengan tujuan untuk menjadi. bersih, sebagai bagian dari ritual keagamaan, ataupun tujuan-tujuan lainnya.

Cuci tangan pakai sabun (CTPS) merupakan salah satu tindakan sanitasi dengan cara membersihkan tangan dan jari jemari menggunakan air dan sabun yang dilakukan oleh manusia untuk menjadi bersih dan memutuskan mata rantai penyakit. Mencuci tangan dengan sabun juga dikenal sebagai salah satu upaya untuk pencegahan penyakit.

Mencuci tangan dengan air yang tidak bersih banyak mengandung kuman dan bakteri penyebab penyakit. Bila digunakan, kuman akan pindah pada saat makan, kuman dengan cepat masuk kedalam tubuh, dan bisa menimbulkan penyakit. Sabun dapat membersihkan dan membunuh kuman, karena tanpa sabun kotoran dan kuman masih tertinggal di tangan.

Penyakit diare merupakan penyakit yang berbasis lingkungan. Dua faktor yang dominan untuk penyakit diare adalah sarana air bersih dan jamban. Dari dua faktor tersebut saling berinteraksi dengan perilaku manusia.

Berdasarkan data kesehatan Kabupaten Pesawaran tahun 2013, jumlah penderita penyakit diare untuk Kecamatan Gedong Tataan sebanyak 2.693 kasus. Dari 2.693 tersebut, separuhnya menyerang anak usia sekolah (usia 6-12 tahun). Data Puskesmas Gedong Tataan tahun 2014, hanya 19 dari 40 anak yang mengetahui dan menerapkan CPTS di sekolah. Dilakukan studi pendahuluan pada tanggal 15 April 2015, didapatkan 7 dari 10 siswa tidak mengetahui tentang cara mencuci tangan yang benar. Penelitian bertujuan mengetahui gambaran pengetahuan dan perilaku CTPS di sekolah dasar Kecamatan Gedong Tataan, Kabupaten Pesawaran.

\section{METODE}

Penenelitian bersifat deskriptif untuk mengetahui gambaran pengetahuan dan perilaku CTPS pada eluruh murid sekolah dasar di wilayah kerja Puskesmas Gedong Tataan. Populasi penelitian adalah seluruh siswa kelas 
IV dan V yang berjumlah 1878 siswa.

Sampel dipilih secara acak proporsional berdasarkan jumlah siswa pada setiap sekolah dasar. Jumlah sampel sebanyak 92 orang siswa, dihitung mengikuti Ariawan, I (1998), pada $\mathrm{P}=0,5 ; \mathrm{Q}=0,5 ; \mathrm{d}=0,1 ;$ alpha $=0,05$.

Pengumpulan data dilakukan dengan melakukan pengamatan (observasi) langsung pada setiap SD, serta wawancara menggunakan kuesioner. Keseluruhan data dianalisis dengan SPSS, dan disajikan dalam bentuk distribusi frekuensi dan persentase dari tiap variabel.
HASIL

\section{Pengetahuan CTPS}

Pengetahuan siswa untuk mengetahui CTPS sangatlah penting, dimana pengetahuan mereka tentang CTPS akan mempengaruhi tingkat kesehatan mereka. Hasil penelitian mendapatkan bahwa sebanyak $70 \%$ siswa memiliki pengetahuan baik.

\section{Tabel 1. Pengetahuan CTPS}

\begin{tabular}{lcc}
\hline \multicolumn{1}{c}{ Tingkat pengetahuan } & F & $\%$ \\
\hline Baik & 65 & 70,7 \\
Kurang Baik & 27 & 29,3 \\
\hline
\end{tabular}

Tabel 2. Komponen Pengetahuan CPTS

\begin{tabular}{llllll}
\hline \multirow{2}{*}{ No } & \multirow{2}{*}{ Komponen Pengetahuan } & \multicolumn{3}{c}{ Ya } & \multicolumn{3}{c}{ Tidak } \\
\cline { 3 - 6 } & & $\mathrm{n}$ & $\%$ & $\mathrm{n}$ & $\%$ \\
\hline 1 & Pengertian cuci tangan pakai sabun & 87 & 94,6 & 5 & 5,4 \\
2 & Perlunya mencuci tangan menggunakan sabun & 58 & 63 & 34 & 37 \\
3 & Penyakit yang disebabkan bila tidak mencuci tangan & 84 & 91,3 & 8 & 8,7 \\
4 & Penyebab penyakit diare & 43 & 46,7 & 49 & 53,3 \\
5 & Siklus penyebaran penyakit melalui tangan & 81 & 88,1 & 68 & 11,9 \\
6 & Manfaat mencuci tangan pakai sabun dan air bersih & 59 & 64,1 & 33 & 35,9 \\
7 & Alasan mencuci tangan harus menggunakan sabun & 46 & 50 & 46 & 50 \\
8 & Pengertian air bersih & 62 & 67,4 & 30 & 32,6 \\
9 & Tempat mencuci tangan pakai sabun & 59 & 64,1 & 33 & 35,9 \\
10 & Alasan penggunaan air bersih untuk mencuci tangan & 78 & 84,8 & 14 & 15,2 \\
\hline
\end{tabular}

\section{Fasilitas mencuci tangan di sekolah}

Kepemilikan fasilitas CTPS yang ada pada sekolah dasar di wilayah kerja Puskesmas Gedong Tataan masih relatif rendah. Hanya $25 \% \quad(\mathrm{~N}=40)$ sekolah yang telah memiliki fasilitas CTPS secara lengkap, seperti tempat untuk mencuci tangan, tersedia air bersih, air yang digunakan adalah air yang mengalir, serta tersedia sabun dan lap. Jumlah sekolah dasar berdasarkan kepemilikan fasilitas CTPS disajikan pada Tabel 3 .

Tabel 3. Distribusi Sekolah Dasar Menurut Kepemilikan Fasilitas CPTS

\begin{tabular}{llllll}
\hline \multirow{2}{*}{ No } & \multirow{2}{*}{ Komponen Fasilitas CTPS } & Ada & \multicolumn{3}{c}{ Tidak } \\
\cline { 3 - 5 } & & $\mathrm{n}$ & $\%$ & $\mathrm{n}$ & $\%$ \\
\hline 1 & Tersedia tempat untuk mencuci tangan & 15 & $37,5 \%$ & 25 & $62,5 \%$ \\
2 & Tersedia air bersih & 12 & $30 \%$ & 28 & $70 \%$ \\
3 & Menggunakan air bersih yang mengalir & 10 & $25 \%$ & 30 & $75 \%$ \\
4 & Tersedia sabun & 8 & $20 \%$ & 32 & $80 \%$ \\
5 & Tersedia lap & 5 & $12,5 \%$ & 35 & $87,5 \%$ \\
Jumlah fasilitas CTPS & 10 & $25 \%$ & 30 & $75 \%$ \\
\hline
\end{tabular}

\section{Perilaku cuci tangan pakai sabun}

Perilaku merupakan suatu proses tertentu dan berlangsung dalam interaksi manusia dan lingkungannya. Tabel 4 menunjukkan bahwa proporsi siswa yang memiliki perilaku CPTS sebanyak $50 \%$.
Tabel 4. Perilaku CTPS

\begin{tabular}{lcc}
\hline \multicolumn{1}{r}{ Perilaku } & F & $\%$ \\
\hline Baik & 46 & 50 \\
Kurang Baik & 46 & 50 \\
\hline
\end{tabular}


Tabel 5. komponen perilaku CPTS

\begin{tabular}{|c|c|c|c|c|c|}
\hline \multirow[t]{2}{*}{ No } & \multirow[t]{2}{*}{ Komponen Perilaku } & \multicolumn{2}{|c|}{ Ya memenuhi } & \multicolumn{2}{|c|}{$\begin{array}{l}\text { Tidak } \\
\text { memenuhi }\end{array}$} \\
\hline & & $\mathrm{n}$ & $\%$ & n & $\%$ \\
\hline 1 & Melakukan cuci tangan pakai sabun sebelum makan & 61 & 66,3 & 31 & 33,7 \\
\hline 2 & Melakukan cuci tangan setelah buang air kecil & 53 & 57,6 & 39 & 42,4 \\
\hline 3 & Melakukan cuci tangan setelah memegang binatang & 54 & 58,7 & 38 & 41,3 \\
\hline 4 & Mencuci tangan hanya sctelah buang air besar & 11 & 12,0 & 81 & 88,0 \\
\hline 5 & Melakukan gerakkan mencuci tangan dengan benar & 49 & 53,3 & 43 & 46,7 \\
\hline
\end{tabular}

\section{PEMBAHASAN}

\section{Pengetahuan Terhadap CPTS}

Berdasarkan hasil penelitian pada 92 siswa di 40 sekolah dasar diketahui bahwa pengetahuan siswa tentang CTPS sudah baik $(70,7 \%)$. Masih terdapat siswa $(29,3 \%)$ yang memiliki tingkat pengetahuan yang kurang baik. Maka diperlukan bimbingan terhadap siswa oleh orang tua, guru, maupun petugas kesehatan dalam memberikan pengetahuan tentang CTPS sehingga siswa dapat berperilaku hidup bersih dan sehat.

Secara umum, siswa sudah mengetahui cara mencuci tangan pakai sabun $(94,6 \%)$. Hanya sebanyak $5,4 \%$ siswa yang perlu mendapatkan pelatihan cara cuci tangan dengan benar. Peran orang tua, guru, dan petugas kesehatan diperlukan dalam meningkatkan pengetahuan dan keterampilan siswa.

Berdasarkan komponen pengetahuan, sebanyak $63 \%$ responden mengetahui perlunya mencuci tangan agar terhindar dari penyakit yang disebabkan oleh tangan yang kotor dan $37 \%$ responden belum mengetahui perlunya mencuci tangan pakai sabun. Sebanyak $91,3 \%$ responden mengetahui penyakit yang disebabkan bila tidak mencuci tangan seperti diare dan cacingan serta sebanyak $8,7 \%$ responden belum mengetahui penyebab bila tidak mencuci tangan. Sebanyak 46,7\% responden sudah mengetahui penyebab dari penyakit diare dan $53,3 \%$ responden belum mengetahui penyebab dari penyakit diare. Sebanyak $88,1 \%$ responden sudah mengetahui siklus penyebaran penyakit melalui tangan yaitu melalui tangan-makanan-mulut dan 11,9\% responden belum mengetahui siklus penyebaran penyakit melalui tangan. Sebanyak $64,1 \%$ responden sudah mengetahui manfaat dari mencuci tangan pakai sabun dan air bersih dan $35,9 \%$ responden belum mengetahui manfaat dari mencuci tangan.
Sebanyak $50 \%$ responden sudah mengetahui kenapa mencuci tangan harus menggunakan sabun dan $50 \%$ responden belum mengetahui kenapa harus mencuci tangan menggunakan sabun. Sebanyak $67,4 \%$ responden sudah mengetahui pengertian dari air bersih dan $32,6 \%$ responden belum mengetahui pengertian dari air bersih. Sebanyak $64,1 \%$ responden sudah mengetahu dimana mereka harus mencuci tangan dan $35,9 \%$ responden belum mengetahui dimana mereka harus mencuci tangan. Serta sebanyak $84,8 \%$ responden sudah mengetahui pentingnya mencuci tangan menggunakan air bersih dan $15,2 \%$ belum mengetahui pentingnya mencuci tangan pakai sabun.

Menurut Notoatmodjo (2012) diperlukan indikator-indikator yang dapat digunakan untuk mengetahui tingkat pengetahuan atau kesadaran terhadap kesehatan, yaitu 1) Pengetahuan tentang sakit dan penyakit; 2) Pengetahuan tentang cara pemeliharaan kesehatan dan hidup sehat; dan 3) Pengetahuan tentang kesehatan lingkungan.

Dengan pengetahuan yang baik terhadap CTPS diharapkan siswa mampu menjaga dirinya sendiri dari penyakit berbasis lingkungan. Pendidikan merupakan suatu usaha untuk mengembangkan kepribadian dan kemampuan siswa di dalam maupun diluar sekolah yang berlangsung seumur hidup. Pendidikan mempengaruhi proses belajar, semakin tinggi pendidikan seseorang maka informasi yang didapatkan akan semakin banyak. Semakin banyak informasi yang didapatkan siswa tentang pentingnya mencuci tangan maka perilaku siswa tersebut akan semakin baik.

Agar hal tersebut dapat terlaksana maka hendaknya diperlukan peran guru, orang tua, dan petugas kesehatan untuk memberikan contoh dalam pelaksanaan perilaku mencuci 
tangan pakai sabun pada siswa dalam kehidupan sehari-hari mereka.

Memiliki tingkat pengetahuan yang baik terhadap perilaku mencuci tangan pakai sabun sangat penting pada usia sekolah. Hal ini dikarenakan banyaknya interaksi anak usia sekolah di dalam kehidupan sehari-hari yang dapat menimbulkan penyakit berbasis lingkungan apabila tidak memiliki pengetahuan yang baik tentang cuci tangan pakai sabun. Memberikan pengetahuan tentang cuci tangan pakai sabun terutama di lingkungan keluarga agar secara bertahap siswa memiliki tingkat pengetahuan yang baik dapat memberikan dampak positif secara luas kepada masyarakat yang ada di lingkungan tempat tinggal dan dapat menurunkan penyakit berbasis lingkungan.

Agar hal tersebut dapat terlaksana dengan baik dibutuhkan peran guru, orang tua, petugas kesehatan untuk memberikan contoh tentang pentingnya mencuci tangan pakai sabun. Jika perilaku cuci tangan pakai sabun telah dilakukan oleh keluarga maka secara bertahap dapat memotifasi masyarakat untuk menurunkan penyakit berbasis lingkungan.

Diperlukan penyuluhan untuk meningkatkan pengetahuan siswa tentang CTPS. Penyuluhan awal dilaksanakan secara langsung, dan diikuti dengan penyuluhan tidak langsung melalui pamflet, banner, poster, dan leaflet.

\section{Fasilitas CTPS Disekolah}

Sarana/fasilitas cuci tangan adalah salah satu bentuk upaya personal hygiene kepada siswa yang menitikberatkan pada upaya pemberian fasilitas cuci tangan untuk membiasakan diri mencuci tangan sebelum dan sesudah mengonsumsi makanan. Unsur utama dalam penyediaan fasilitas cuci tangan ini adalah ketersediaan air bersih mengalir yang memenuhi syarat fisik yaitu air bersih air yang digunakan untuk mencuci tangan adalah air yang mengalir. Adapun tersedia sabun sebagai desinfektan yang diperlukan untuk membunuh bakteri penyebab penyakit yang biasa menghinggapi tangan manusia serta lap sebagai pengering tangan. Bakteri Streptococcus, Pneunomomi, dan E. Coli adalah di antara bakteri yang biasa menghinggapi tangan manusia.

Berdasarkan hasil penelitian diketahui bahwa sekolah dasar yang memiliki fasilitas CPTS baru sebanyak 25\%. Penilaian ketersediaan fasilitas meliputi tersedia tempat untuk mencuci tangan, tersedia air bersih mengalir, tersedia sabun sebagai desinfektan, serta tersedia lap bersih untuk mengeringkan tangan. Kondisi ini meningkatkan risiko penularan penyakit melalui tangan.

Selain ketersediaan sarana pencucian tangan, hal lain yang perlu diperhatikan adalah metode pencucian tangan. Jika fasilitas CPTS telah tersedia tetapi metode cuco tangan masih belum aik, makan tujuan tujuan CPTS tidak akan tercapai. Untuk itu, perlu meningkatkan pengetahuan dan keterampilan tentang CPTS bagi seluruh siswa, dan guru sebagai pengawas.

\section{Perilaku CPTS}

Hasil penelitian menunjukkan bahwa $50 \%$ siswa telah memiliki perilaku CPTS. Menurut Notoatmodjo (2012), perilaku terbentuk melalui suatu proses tertentu, dan berlangsung dalam interaksi manusia dengan lingkungannya. Faktor-faktor yang memegang peranan dalam pembentukan perilaku adalah 1) Faktor internal, berupa kecerdasan, persepsi, motivasi, emosi dan sebagainya; 2) Faktor eksternal, meliputi objek, orang, kelompok, dan lain-lain.

Perilaku yang dipraktikkan olch peserta didik, guru dan masyarakat lingkungan sekolah atas dasar kesadaran sebagai hasil pembelajaran, sehingga secara mandiri mampu mencegah penyakit, meningkatkan kesehatannya, serta berperan aktif dalam menjaga kesehatan. Skinner dalam Notoatmodjo (2012) merumuskan bahwa perilaku merupakan respon atau reaksi seseorang terhadap rangsangan dari luar (stimulus).

Dari hasil penelitian diketahui bahwa sebanyak $50 \%$ siswa masih memiliki perilaku kurang baik. Anak-anak merupakan kelompok yang paling rentang terhadap perilaku yang tidak sehat. Dengan perilaku yang baik diharapkan siswa mampu menjaga dirinya sendiri agar terhindar dari penyakit. Salah satu faktor yng mempengaruhi perilaku siswa adalah tingkat pengetahuan yang masih rendah. Menurut Notoatmodjo (2003), perilaku seseorang tentang kesehatan dipengaruhi oleh pengetahuan sebagai predisposing factor dalam perubahan perilaku. Untuk meningkatkan perilaku CTPS di sekolah, perlu upaya untuk meningkatkan pengetahuan siswa tentang pentingnya CPTS.

\section{KESIMPULAN}


1. Sebanyak $70,7 \%$ responden siswa telah memiliki pengetahuan yang baik tentang CPTS.

2. Sebanyak $75 \%$ (total 40 ) sekolah belum memiliki fasilitas CPTS.

3. Sebanyak $50 \%$ (total 92) siswa telah memiliki perilaku yang baik tentang CPTS.

DAFTAR PUSTAKA

DEPKES. 2003. Kamus Besar Bahasa Indonesia. Jakarta: Balai Pustaka. Edisi Revisi.

Ariawan, Iwan. 1998. Besar dan Metode Sampel pada Penelitian Kesehatan. Jakarta: Universitas Indonesia.

Kepmenkes RI. 2009. Keputusan Menteri Kesehatan RI Nomor 374/MENKES/SK/V/2009 Tentang Sistim Kesehatan Nasional. Jakarta.

Mencuci_tangan.2013(http://id.wikipedia.org) [21 maret 2015 jam 15.20].
Mencuci_tangan_dengan_sabun.2014 (http://id.wikipedia.org/wiki) $[21$ maret 2015 jam 16.00].

Notoatmodjo, Soekidjo. 2003. Pendidikan Dan Perilaku Kesehatan. Jakarta: Renika Cipta.

2005. Metode penelitian kesehatan. Jakarta: Renika cipta.

2005. Metode penelitian kesehatan. Jakarta: Renika cipta.

2012. Promosi Kesehatan Dan Perilaku Kesehatan. Jakarta: Renika Cipta.

Proverawati, Atikah, Eni Rahmawati. 2012. Perilaku : Hidup Bersih Dan Sehat. Yogyakarta: Nuha Medika.

Sapta, Wibowo Ady, dkk. 2013. Panduan Penyusunan Karya Tulis Ilmiah. Politeknik Kesehatan Kemenkes Tanjungkarang, Lampung. 